\title{
Comparisons of Codal Detailing Rules for Curvature Ductility and Numerical Investigations
}

\author{
Michelangelo Laterza ${ }^{1, *}$, Michele D’Amato ${ }^{1}$, Laksiri P. Thanthirige ${ }^{1}$, Franco Braga ${ }^{2}$ and \\ Rosario Gigliotti ${ }^{2}$
}

${ }^{I}$ DiCEM, Department of Architecture, Environment, Cultural Heritage: University of Basilicata, Via Lazazzera, 75100 Matera, Italy; ${ }^{2}$ DiSG, Department of Structural Engineering, "Sapienza" University of Rome, Via Eudossiana, 00185, Rome, Italy

\begin{abstract}
In moment resisting frame structures special detailing rules are applied to critical regions of primary columns and beams to ensure adequate curvature ductility. This is necessary for dissipating earthquake energy through hysteretical behavior of critical regions where inelastic flexural excursions occur. In this paper codal detailing rules for designing longitudinal and transverse reinforcement of primary elements as function of curvature ductility are assessed. Four seismic codes are considered: Italian code, New Zealand code, Eurocode 8 and American code. Non-linear monotonic momentcurvature analyses are performed on some sections of columns and beams detailed in according to the considered codal provisions. In the analyses the confinement effects within the concrete core have been taken into account as well. The paper concludes comparing the measured curvature ductility of the studied sections with the expected one by the codal provisions within the critical regions.
\end{abstract}

Keywords: Critical regions, curvature ductility, design equations, longitudinal reinforcement, RC beams, RC columns, transverse reinforcement.

\section{INTRODUCTION}

Structural damaging is a widespread design strategy of reinforced concrete (RC) moment resisting frames against severe earthquakes. It consists of allowing flexural inelastic excursions in primary elements ends (usually defined 'critical regions') without a substantial reduction of their carrying capacity of vertical loads. If shear failures are avoided and flexural inelastic excursions can take place in beams rather than in columns (strong columns-weak beams mechanism) then a significant reduction of seismic actions and internal forces are obtained in designing a structure.

For allowing large flexural inelastic excursions special proportioning and detailing rules to primary element ends are required. These rules are mainly addressed to ensure an adequate concrete confinement level within section core and to prevent the premature buckling of compressed longitudinal bars. In this way high curvature ductility in critical regions can be reached coherently with the expected structural dissipative capacity.

In this paper the special provisions of RC beams and columns reported in the following seismic codes are compared: Eurocode8 (EC8 2004) [1], Italian code (NTC-08 2008) [2], New Zealand code (NZS-3101 2006) [3] and American code (ACI-318 2008) [4]. The studied codes are interesting since they explicitly link the amount of longitudinal and transverse reinforcement to the curvature ductility of critical regions.

*Address correspondence to this author at the DiCEM, Department of Architecture, Environment, Cultural Heritage: University of Basilicata, Via Lazazzera, 75100 Matera, Italy; Tel: +39 0835 1971462;

Fax: +390835 1971497; E-mail: michelangelo.laterza@unibas.it
Then monotonic non-linear moment curvature analyses on detailed RC sections are performed in order to analytically evaluate the available curvature ductility and to compare it with the curvature ductility demand. The analyses are carried out with an open source software framework (OpenSees 2009) [5], accounting also for confinement effects within section core with the BGL model (Braga et al. 2006, D'Amato et al. 2012) [6, 7].

\section{CURVATURE DUCTILITY OF AN RC SECTION}

A moment-curvature diagram ( $M-\phi$ curve) essentially indicates the flexural capacity beyond elastic limit and the hysteretic energy that can be dissipated by an RC primary element at section level. It is classically obtained for a given value of axial load by increasing the axial strains profile up to the section failure with the plane section assumption (Fig. 1). By knowing the stress-strain curves of concrete and steel, the imposed curvature and the related moment may be determined with the strains compatibility and equilibrium of forces.

Starting from the obtained $M-\phi$ diagram, the curvature ductility $\mu_{\phi}$ of a section is given by the following expression:

$$
\mu_{\phi}=\frac{\phi_{u}}{\phi_{y}}
$$

where $\phi_{u}$ and $\phi_{y}$ are the ultimate and the yielding curvature of the section, respectively (Fig. 2).

Since the $M$ - $\phi$ diagram is a non-linear curve, $\phi_{\mathrm{u}}$ and $\phi_{\mathrm{y}}$ are usually individuated on a conventionally-derived bilinear equivalent curve, which represents an idealization of the actual $M-\phi$ curve. 


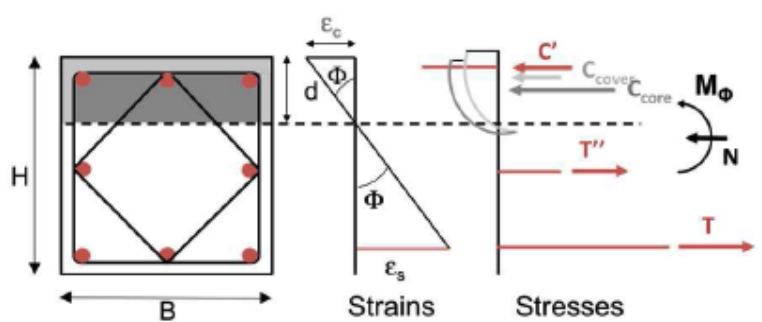

Fig. (1). Stresses and strains over the transverse section.

The curvature ductility of a section in this work has been evaluated as proposed by Watson et al. (1994) [8]. With this approach, the yielding curvature $\phi_{\mathrm{y}}$ is expressed as (Fig. 2):

$$
\phi_{y}=\phi_{y}^{\prime} \frac{M_{y}}{M_{y}^{\prime}}
$$

where $\phi_{y}{ }^{\prime}$ and $M_{y}$ ' are, respectively, the curvature and the corresponding moment calculated when the steel in tension is yielded or when the concrete extreme fiber in compression reaches the strain value of 0.002 , whichever occurs first. Whereas, the ultimate curvature $\phi_{u}$ is the curvature corresponding to one of the following limit conditions reached:

1. the moment resisted at either the positive or negative branch of the $M-\phi$ curve has reduced to $0.8 M_{i}$, where $M_{i}$ is flexural strength peak of the section;

2. the strain energy accumulated in the transverse steel has become equal to its strain-energy absorption capacity;

3. the tensile strain in the longitudinal reinforcing steel has exceeded $\varepsilon_{s u}$, where $\varepsilon_{s u}$ is the strain at the ultimate tensile strength;

4. the compressive strain in the longitudinal steel has exceeded $\varepsilon_{s u c}$, where $\varepsilon_{s u c}$ is the strain when buckling occurs.

In this study only the first three failure conditions have been considered. In accordance with $[1,2]$ the premature buckling of compressed longitudinal bars has been assumed to be delayed respecting the rule that the spacing hoops $S$ normalized by the longitudinal bar diameter $d_{b L}$ is always less than 6. In fact, it is known that in order to fulfill the required curvature ductility the buckling of compressed bars is adequately delayed by reducing the slenderness through the $s / d_{b L}$ ratio. Interesting analytical and experimental aspects regarding the local buckling of longitudinal rebars may be found in [9-11] where also the effects of additional external FRP wraps are investigated.

\section{CODAL PROVISIONS FOR LOCAL CURVATURE DUCTILITY}

As it is well known, the curvature ductility of a section is strictly depending on the spaced transverse reinforcements in the form of closed stirrups, ties, hoops or spirals, especially when high axial load acts on a RC section. This is due to the fact that transverse reinforcements contrast lateral expansion of compressed section core and apply a restraining pressure improving significantly strength and ductility of concrete.

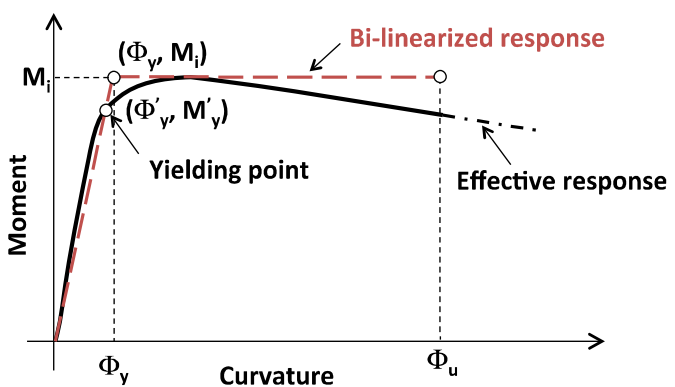

Fig. (2). Moment-curvature curve and the bilinear idealized equivalent one [8].

Moreover, reducing the slenderness of longitudinal compressed bars the local buckling is delayed and high curvature of the section may be reached [6, 8-11].

In this paper are being investigated the special detailing rules of some seismic codes. These rules are required to critical regions of primary columns and beams for ensuring a curvature ductility level coherent with the global ductility class of a structure. The seismic codes considered in this work are: the Eurocode 8 (EC8 2004) [1], the Italian Code (NTC-08 2008) [2], the New Zealand Code (NZS-3101 2006) [3], and the American Code (ACI-318 2008) [4]. At first, detailing rules of each code are being separately discussed. Then, in order to compare the actual curvature ductility with the expected one a series of analytical investigations are performed with OpenSees (2009) [5], by considering some RC sections detailed with the rules examined.

\subsection{RC Primary Columns}

\subsubsection{Eurocode 8 (EC8, 2004)}

Eurocode $8(\mathrm{EC} 8,2004)$ [1] requires a curvature ductility $\mu_{\phi}$ to all critical regions of primary seismic elements, including columns ends, in according to the following expression:

$$
\mu_{\phi}= \begin{cases}2 q_{0}-1 & {\left[T_{1} \geq T_{c}\right]} \\ 1+2\left(q_{0}-1\right) T_{c} / T_{1} & {\left[T_{1}<T_{c}\right]}\end{cases}
$$

where $T_{1}$ is fundamental period of the building in the horizontal direction of interest;

$T_{c}$ is the limit of the constant acceleration region of the elastic response spectrum;

$q_{o}$ is the basic value of the behavior factor defined according to the structural type adopted.

The EC8 ductility demand is reported in Fig. (3) as function of the fundamental period $T_{1}$, and considering the ground type from A to E. Two behavior factors are considered: $\mathrm{q}_{0}=5.85$ and $\mathrm{q}_{0}=3.9$, related to high $(\mathrm{DCH})$ and medium (DCM) ductility class, respectively. The values of $\mu_{\phi}$ in Fig. (4) are multiplied by the factor 1.5 as indicated in EC8.

By comparing all curves of Fig. (3) it is easy to note that when the fundamental period $T_{1}$ is greater than $0.5 \mathrm{sec}$, the curvature ductility demand is only depending on the structural ductility class. In this case the values of $\mu_{\phi}=16$ and $\mu_{\phi}=10$ are obtained in the case of $\mathrm{q}=5.85$ and $\mathrm{q}=3.9$, respectively. 


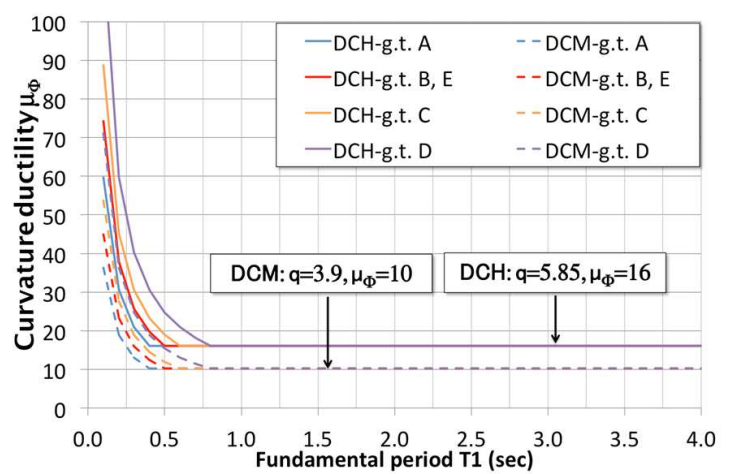

Fig. (3). Curvature ductility demand in according to EC8 [1].

At the base of primary seismic columns the curvature ductility demand is satisfied if the transverse reinforcement is designed according to the following equation:

$$
\alpha \omega_{w d} \geq 30 \mu_{\phi} v_{d} \varepsilon_{s y, d} \frac{b_{c}}{b_{0}}-0.035
$$

where $\omega_{w d}$ is the mechanical ratio of transverse reinforcement given by the ratio:

$$
\omega_{w d}=\frac{\text { Volume of confining hoop }}{\text { Volume of concretecore }} \frac{f_{y d}}{f_{c d}}
$$

where $v_{d}$ is the normalized design axial force given by $N_{E d} / A_{c} f_{c d}$;

$\varepsilon_{s y, d}$ is the design value of tension steel strain at yield;

$h_{c}$ is the gross cross-sectional depth parallel to the horizontal direction in which the value of $\mu_{\phi}$ is considered;

$h_{o}$ is the depth of confined core (to the center-line of the hoops);

$b_{c}$ is the gross cross-sectional width;

$b_{o}$ is the width of confined core (to the center-line of the hoops); $\alpha_{n} \alpha_{s}$.

$\alpha$ is the confinement effectiveness factor, equal to $\alpha=$

The Eq. 4 shows that curvature ductility proportionally increases with the mechanical volumetric ratio of confining hoops $\left(\omega_{w d}\right)$ within the critical regions. The effectiveness of the confinement is also considered depending on the arrangement of the hoops and longitudinal bars (through $\alpha$ parameter).

In addition to the amounts given by the Eq. (4), the EC8 indicates minimum values of $\omega_{w d}$ to provide within critical regions of columns as well. As far as structures of high ductility class $(\mathrm{DCH})$ are concerned, a minimum value of $\omega_{w d}=0.12$ is required at the base of the primary seismic columns. Instead, in all columns critical regions above the base the minimum mechanical ratio is $\omega_{w d}=0.08$. Whereas, in the case of structures of medium ductility class (DCM) the EC 8 requires a minimum value of $\omega_{w d}=0.08$ at the base of primary columns, while the minimum spacing rules are only required above the base of columns.

\subsubsection{Italian Code (NTC-08, 2008)}

The Italian Code (NTC-08, 2008) [2] applies at the base of primary seismic columns the same minimum amounts of EC8 for transverse reinforcement. Moreover, differently from EC8, this code extends these minimum amounts also above the base and outside the critical regions of primary columns.

At base and in the critical regions above the base of primary columns of structures with High Ductility Class (indicated as CD"A"), the following design equation of transverse reinforcement has to be applied:

$$
\omega_{w d}=\frac{A_{s h}}{b s} \frac{f_{y d}}{f_{c d}} \geq 0.12
$$

Whereas, to all columns critical regions at base and above the base of structures of Low Ductility Class (indicated as CD"B"), and outside the critical regions of columns of CD"A" the required transverse amount becomes:

$$
\omega_{w d}=\frac{A_{s h}}{b s} \frac{f_{y d}}{f_{c d}} \geq 0.08
$$

It must be realized that Eq. 6 expresses, according to free body diagram schematization, the ratio of confining pressure within the section core to the unconfined concrete strength. Infact, the Eq. 6 can be rewritten as:

$$
\omega_{w d}=\frac{f_{l}}{f_{c d}}
$$

where the confining pressure $f_{l}$ is given by:

$$
f_{l}=\frac{A_{s h}}{b s} f_{y d}
$$

\subsubsection{New Zealand Code (NZS-3101, 2006)}

Coherently with the structural ductility class assumed, the New Zealand Code (NZS-3101 2006) [3] requires the following curvature ductility to critical regions of primary elements: $\mu_{\phi}=20$ for ductile structures (behavior factor $\mathrm{q}=6$ ), and $\mu_{\phi}=10$ for structures of limited ductility ( $q=3$ ).

In accordance with NZS-3101, the curvature ductility demand is satisfied if design equations of transverse reinforcements reported in the Eq. (9) and Eq. (10) are applied to critical regions of primary columns. More details on these design equations may be found elsewhere (Watson et al. 1994) [8].

Rectangular Sections

$$
\rho_{s}=\left\{\frac{A_{g}}{A_{c}} \frac{\left[\left(K_{c} \phi_{u} / \phi_{y}\right)-33 \rho_{t} m+22\right]}{111} \frac{f_{c}^{\prime}}{f_{y t}} \frac{N_{0}^{*}}{\phi f_{c}^{\prime} A_{g}}\right\}-0.006
$$

\section{Circular Sections}

$$
4 \rho_{s}=1.4\left\{\frac{A_{g}}{A_{c}} \frac{\left[\left(K_{c} \phi_{u} / \phi_{y}\right)-33 \rho_{t} m+22\right]}{111} \frac{f_{c}^{\prime}}{f_{y t}} \frac{N_{0}^{*}}{\phi f_{c}^{\prime} A_{g}}\right\}-0.008
$$

where $\rho_{s}$ is the volumetric ratio of transverse reinforcement given by:

$$
\rho_{s}=\frac{A_{s h}}{s_{h} h^{\prime \prime}}
$$


$A_{s h}$ is total effective area of transverse bars in direction under consideration within center-to-center spacing hoop sets;

$s_{h}, h$ " are the dimensions of core rectangular or square column at right angles to direction of transverse bars under consideration measured to center to the center line of the perimeter hoop;

$A_{g}, A_{c}$ are the gross and the core area of column;

$\phi_{u} / \phi_{y}$ is the curvature ductility factor;

$\rho_{t}=A_{s t} / A_{g}, A_{s t}$ is the total area of the longitudinal reinforcement;

$m=f_{y} / 0.85 f^{\prime}, f_{y}$ is the yielding strength of the longitudinal reinforcement;

$f_{y t}$ is the yielding strength of transverse steel;

$f^{\prime}{ }^{\prime}$ is concrete compressive cylinder strength;

$N^{*}$ is axial compressive load on column;

$\phi$ is the strength reduction factor;

$\rho_{s}$ is the ratio of volume of transverse circular hoops or spiral steel to concrete core of the column.

\subsubsection{American Code (ACI-318, 2008)}

The American code (ACI 318-08, 2008) [4] provides the volumetric ratio of transverse reinforcement as the larger value calculated with following equations:

Rectangular Sections

$$
\begin{aligned}
& \rho_{s}=0.3 \frac{f_{c}^{\prime}}{f_{y t}}\left[\frac{A_{g}}{A_{c}}-1\right] \\
& \rho_{s}=0.09 \frac{f_{c}^{\prime}}{f_{y t}}
\end{aligned}
$$

\section{Circular Sections}

$$
\begin{aligned}
& \rho_{s}=0.45 \frac{f_{c}^{\prime}}{f_{y t}}\left[\frac{A_{g}}{A_{c}}-1\right] \\
& \rho_{s}=0.12 \frac{f_{c}^{\prime}}{f_{y t}}
\end{aligned}
$$

\subsubsection{Comparisons Among Transverse Reinforcement Amounts}

In this paragraph the comparisons are reported among transverse reinforcement amounts required by the considered codes. It has been considered a square section of $300 \mathrm{~mm} \mathrm{x}$ $300 \mathrm{~mm}$, with concrete unconfined strength of $f^{\prime}{ }_{c}=30 \mathrm{MPa}$, and steel tensile strength of $f_{y}=400 \mathrm{MPa}$. The comparisons among codal design equations are performed in terms of mechanical ratio $\omega_{w d}$ of transverse reinforcement, by varying the axial load ratio $v_{d}$. In the analyzed cases four amounts of longitudinal reinforcement $\rho_{t} m(0.1,0.2,0.3$ and 0.4$)$ and four values of curvature ductility $\mu_{\phi}(5,10,15$ and 20) have been considered (Fig. 4).

It is easy to recognize that in the analyzed cases the transverse amounts required by the EC8 (Eq. 4) significantly differ from the other ones. Instead, the minimum values of EC8 (and by NTC- 08 code) are closer to the ones obtained with the NZS-3101 design equation (Eq. 9). Finally, the minimum amount required by ACI-318 is higher than the one indicated by EC8.
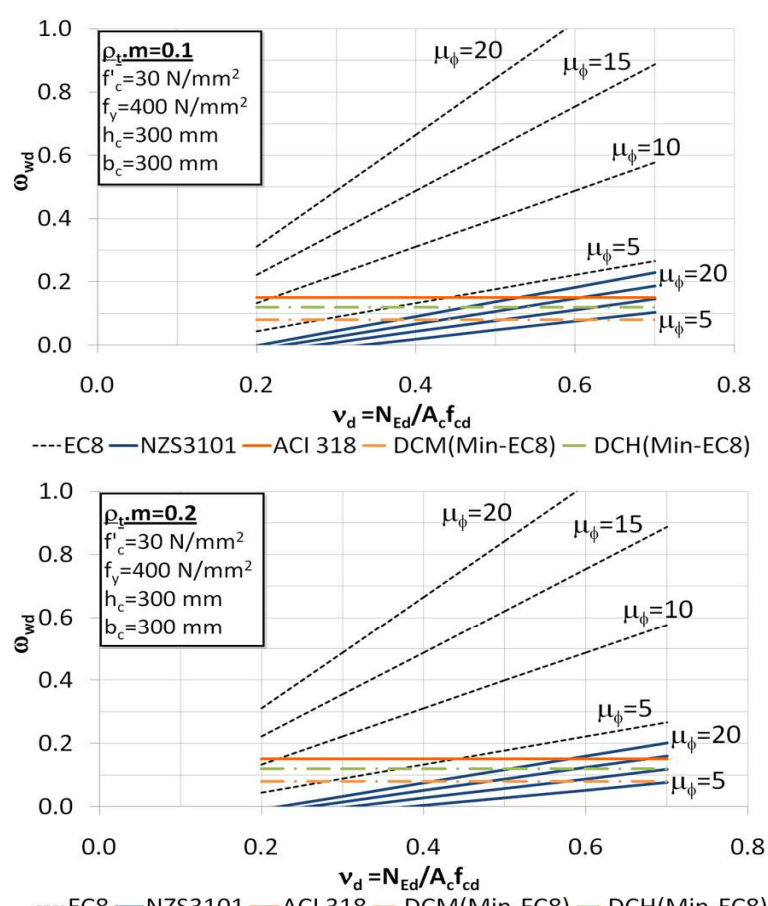

$----E C 8-N Z S 3101-A C I 318-$ DCM(Min-EC8) - DCH(Min-EC8)

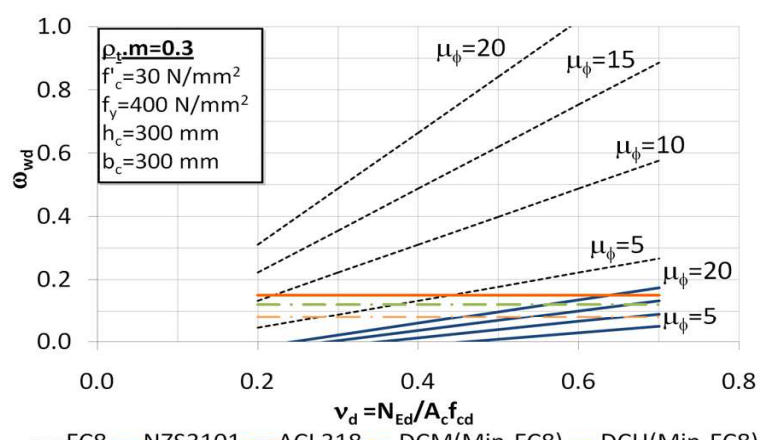

---EC8 - NZS3101 - ACl 318 - DCM(Min-EC8) - DCH(Min-EC8)

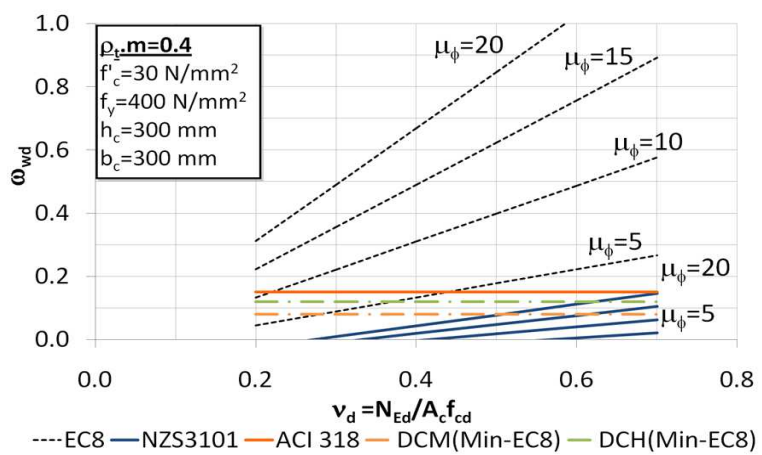

Fig. (4). Comparisons among transverse reinforcement amounts for different values of $\rho_{t} m$.

\subsection{RC Primary Beams}

$\mathrm{RC}$ beams are elements in which the acting axial load does not govern their flexural response. For example, the EC8 classifies as beams RC elements that are subjected to a normalized design axial force $v_{d}=N_{E d} / A_{c} f_{c d}$ lower than 0.1 . 


\subsubsection{EC8 and NTC-08 Code}

The EC8 links the maximum amount of beam longitudinal reinforcement in tension to the required local curvature ductility as follows:

$$
\rho_{\max }=\rho^{\prime}+\frac{0.0018}{\mu_{\phi} \varepsilon_{s y}} \frac{f_{c d}}{f_{y d}}
$$

where

$\rho_{\max }$ is the maximum reinforcement ratio in tension normalized to $b d$; to $b d$;

$\rho$ ' is the reinforcement ratio in compression normalized $\varepsilon_{s y}$ is tension steel strain at yielding.

A minimum amount of longitudinal reinforcement in tension is also required:

$$
\rho_{\min }=0.5\left(\frac{f_{c t m}}{f_{y k}}\right)
$$

where

$f_{c t m}$ is the mean value of tensile strength of concrete;

$f_{y k}$ is the characteristic value of the yielding strength of reinforcing steel.

Similarly to the EC8, the Italian code NTC-08 provides a range of longitudinal reinforcement amount in tension for ensuring adequate curvature ductility within the critical regions. In this formulation there is not an explicit dependence on curvature ductility for the maximum amount of longitudinal reinforcement (Eq. 18):

$$
\frac{1.4}{f_{y k}}<\rho<\rho_{\text {comp }}+\frac{3.5}{f_{y k}}
$$

Moreover, both NTC-08 and EC8 require that in the critical regions of beams at least half of longitudinal reinforcement in tension has to be placed in compression, that is:

$$
\rho^{\prime} \geq 0.5 \rho
$$

\subsection{2. $N Z S-3101$}

The NZS-3101 code limits the tension reinforcement ratio $\rho$ within the critical regions with the following expression:

$$
\rho_{\max }=\frac{f_{c}^{\prime}+10}{6 f_{y}} \leq 0.025
$$

\subsubsection{Comparisons Among Codal Provisions}

In according to the design equations of longitudinal reinforcement of beams previously discussed, in Fig. (5) are reported the values of $\rho_{\max }$ by varying $\rho^{\prime}$, considering four values of the curvature ductility $\mu_{\phi}(5,10,15$ and 20$)$. The comparisons refer to three different values of concrete strength: $f^{\prime}{ }_{c}=25,30$ and $35 \mathrm{MPa}$.

In Fig. (5) is highlighted the area where the prescription of Eq. (19) is satisfied, taking into account also the inversion of the bending moments due to seismic action in the beams ends.

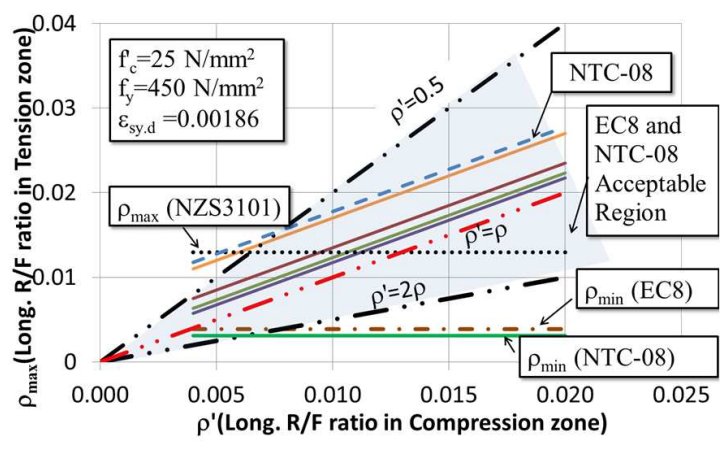

$\mathrm{EC} 8-\mu \phi=5 \quad \mathrm{EC} 8-\mu \phi=10 \quad \mathrm{EC} 8-\mu \phi=15 \quad \mathrm{EC} 8-\mu \phi=20$

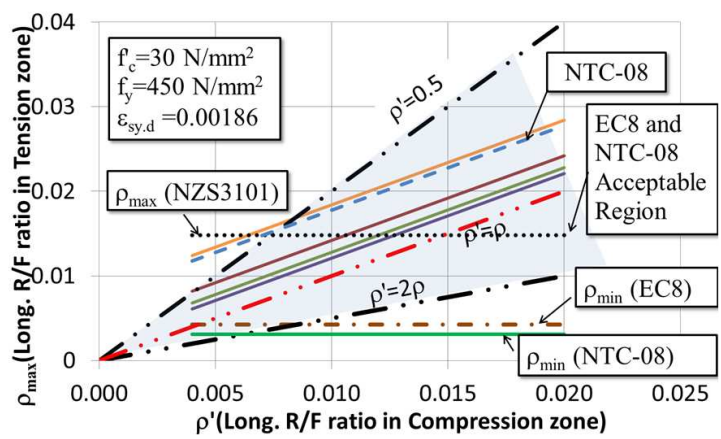

$\mathrm{EC} 8-\mu \phi=5 \quad \mathrm{EC} 8-\mu \phi=10 \quad \mathrm{EC} 8-\mu \phi=15 \quad \mathrm{EC} 8-\mu \phi=20$

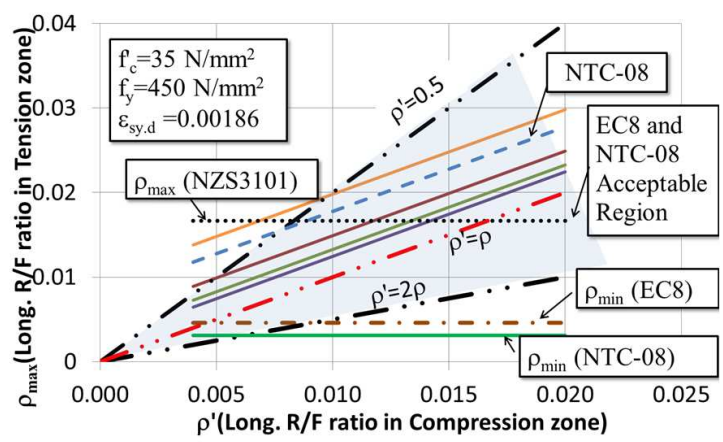

$\mathrm{EC} 8-\mu \phi=5 \quad \mathrm{EC} 8-\mu \phi=10 \quad \mathrm{EC} 8-\mu \phi=15 \quad \mathrm{EC} 8-\mu \phi=20$

Fig. (5). Comparisons of $\rho_{\max }$ by varying $\rho$ ' and the curvature ductility: a) $\left.\mathrm{f}_{\mathrm{c}}=25 \mathrm{MPa}, \mathbf{b}\right) \mathrm{f}_{\mathrm{c}}{ }^{\prime}=30 \mathrm{MPa}$, and c) $\mathrm{f}_{\mathrm{c}}=35 \mathrm{MPa}$.

Therefore, the Eq. (19) can be rewritten as:

$$
0.5 \rho<\rho<2 \rho
$$

The comparisons of the Fig. (5) reveal that the Eq. (16) reported in the EC8 and the NTC-08 code refers only to the cases when $\rho^{\prime} / \rho_{\max }<1$ (reinforcement amount in compression lower than the one in tension). Moreover, the higher the ratio $\rho^{\prime} / \rho_{\max }$ the higher the beams curvature ductility.

When the ratio $\rho^{\prime} / \rho_{\max }$ tends to 1 (the dashed red line) the curvature ductility that can be reached within beams critical regions is theoretically infinity. Only the NZS-3101 code considers the $\rho_{\max }$ parameter independent from the ratio of reinforcement in compression (Eq. 20).

Relatively to the cases analyzed, the NTC-08 provides values of $\rho_{\max }$ (the blue dashed line) in better agreement with 
the ones of the EC8 (the orange continuous line) when the curvature ductility is equal to 5 (the lowest scatter is obtained when $f^{\prime}{ }^{\prime}$ is equal to $30 \mathrm{MPa}$ ).

Finally, all considered codal provisions of beams are not depending on the transverse reinforcement amount. Therefore, the spacing rules have to be respected within critical regions only for delaying the buckling of compressed longitudinal bars and not for regulating the confinement level of compressed concrete core.

\section{NUMERICAL INVESTIGATIONS}

A series of monotonic non-linear moment-curvature analyses has been performed with the aim of comparing the available curvature ductility of RC beams and columns sections with the expected one by applying the detailing rules proposed by the considered codes. The actual ductility curvature has been calculated in each analysis upon the momentcurvature relationship bi-linearized as previously described in paragraph 2.

The numerical analyses for beams and columns sections have been carried out with OpenSees (2009) [5] software framework by using a zero-length element object with a fiber section. This object has zero thickness and consists of two nodes (one is completely fixed) placed at the same location. Each analysis has been conducted by assigning at the free end the given axial load and by increasing the axial strains profile over the section until the failure. The free-end rotation recorded at each step of the analysis is the curvature of the zero-length element [5].

The confinement effects provided by transverse reinforcement arrangements within the section core have been taken into account in the analyses with the BGL model (Braga et al. 2006) [6]. Further details of the model implementation could be found in D'Amato et al. 2012 [7].

In the numerical analyses of columns and beams sections an elastic-perfectly plastic stress-strain model has been assumed for the skeleton curve of steel. The adopted properties are reported in Table $\mathbf{1}$.

Table 1. Material properties of steel.

\begin{tabular}{|c|c|c|}
\hline Type of steel & B450C & B450C \\
\hline \hline Tension Curve & Compression Curve \\
\hline Yielding strength & $450 \mathrm{MPa}$ & $450 \mathrm{MPa}$ \\
\hline Ultimate strain & $20 \%$ & $7.5 \%$ \\
\hline $\begin{array}{c}\text { Maximum energy } \\
\text { absorption }\end{array}$ & $79.5 \mathrm{MJ} / \mathrm{m}^{3}$ & $33.25 \mathrm{MJ} / \mathrm{m}^{3}$ \\
\hline
\end{tabular}

\subsection{Numerical Analyses on RC Columns Sections}

Fig. (6) reports details of the considered column section. Totally, about 200 moment-curvature analyses have been conducted by varying the axial load ratio $v_{d}$, the longitudinal reinforcement ratio $\rho_{t}$, and the unconfined concrete strength $f_{c}^{\prime}$. The ranges of all investigated parameters in the analyses are reported in the Table $\mathbf{2}$. In evaluating the confining effects within the core section the contribution of the two in- ternal ties of (Fig. 6) has been ignored. It has been considered only the confinement offered by the external simple hoop (section type "S1" in [6] and [7]).

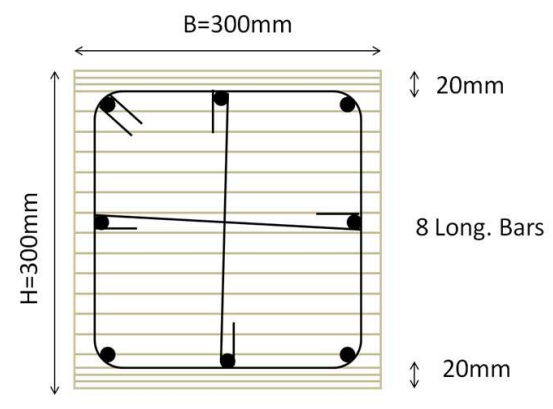

Fig. (6). Column section considered for numerical investigations.

Table 2. Range of parameters investigated.

\begin{tabular}{|c|c|}
\hline Parameters & Range \\
\hline \hline$\phi_{\mathrm{u}} / \phi_{\mathrm{y}}$ & $5-20$ \\
\hline $\mathrm{P} / \mathrm{f}_{\mathrm{c}} \mathrm{A}_{\mathrm{g}}$ & $0.2-0.7$ \\
\hline $\mathrm{F}_{\mathrm{c}}{ }_{\mathrm{c}}(\mathrm{MPa})$ & $30-40$ \\
\hline$\rho_{\mathrm{t}}, \mathrm{m}$ & $0.1-0.4$ \\
\hline $\mathrm{c} / \mathrm{h}$ & 0.02 \\
\hline$\omega_{\mathrm{wd}}$ & $0-0.25$ \\
\hline
\end{tabular}

The results of the performed analyses are reported in Figs. (7-10), in which the assigned mechanical ratio of transverse reinforcement $\omega_{w d}$ is associated to the axial load ratio $v_{d}$ of each moment-curvature analysis. The results are grouped by referring to different values of the actual curvature ductility $\mu_{\phi}(5,10,15$ and 20$)$, and to the different values of $\rho_{t} m(0.1,0.2,0.3$ and 0.4$)$ considered. For sake of clarity, in Figs. (7-10) are also reported the transverse reinforcement amounts required by the studied seismic codes for satisfying the actual curvature ductility.

The comparisons show that in the cases analyzed for a given value of curvature ductility the transverse reinforcement amount increases with the axial load ratio. Moreover, the assigned amounts are in good agreement with the ones indicated by NZS-3101, especially for high axial load.

The EC8 always requires a significantly higher amount of transverse reinforcement with respect to assigned one in the analyses. Instead, the minimum values are sufficient only in the cases of low axial load ratios. The scatter between the assigned transverse reinforcement amount and the EC8 minimum one becomes more evident when the curvature ductility is high.

Starting from the obtained analytical results, it is possible to propose a first formulation of a design equation linking the transverse reinforcement amount with the axial load ratio and the curvature ductility. The design equation, accounting for the parameters investigated, may be derived with a linear regression applying the same approach proposed in a previous work (Braga et al. 2011) [12]: 


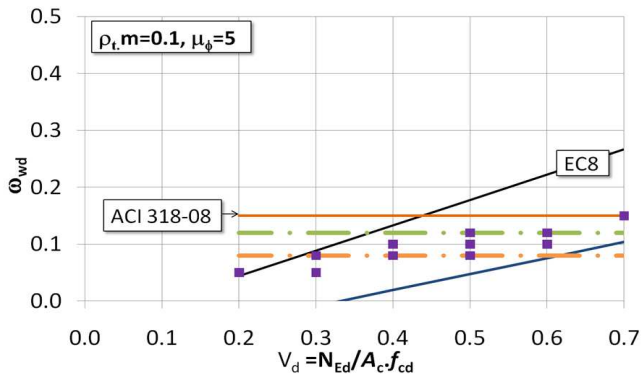

-NZS $3101-\mathrm{DCM}(\mathrm{Min}-\mathrm{EC} 8)-\mathrm{DCH}($ Min-EC8) $=\operatorname{Model}(\mathrm{BGL})$

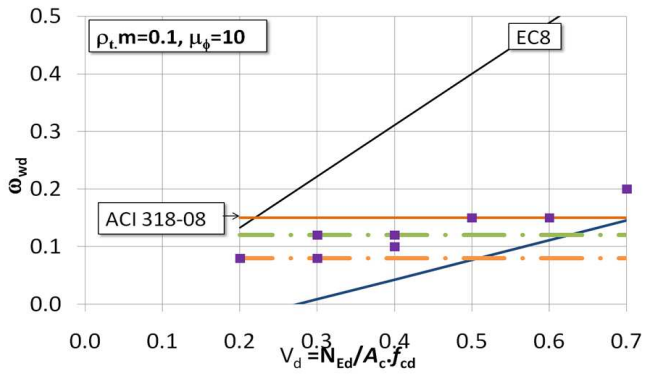

-NZS $3101-\mathrm{DCM}($ Min-EC8) $-\mathrm{DCH}($ Min-EC8) - Model(BGL)

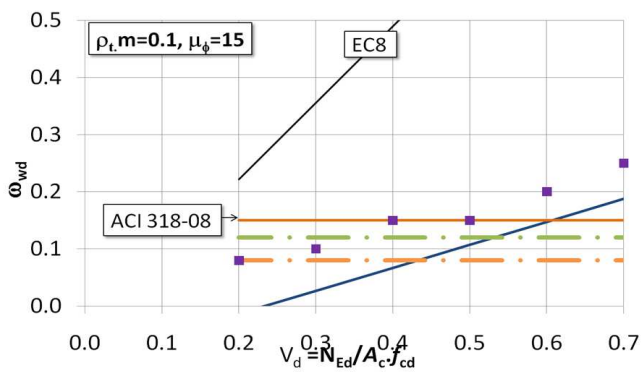

-NZS $3101-\mathrm{DCM}($ Min-EC8) $-\mathrm{DCH}($ Min-EC8) $=\operatorname{Model}(\mathrm{BGL})$

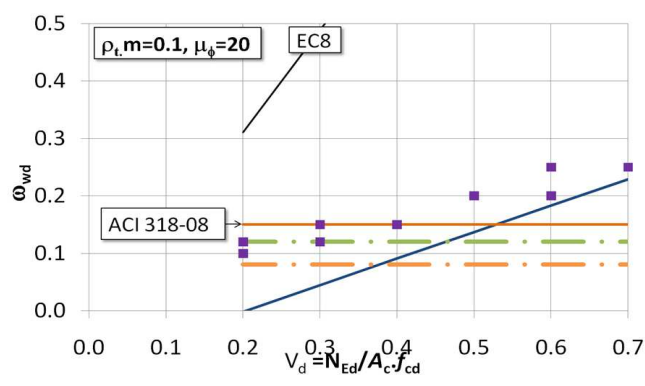

-NZS $3101-\mathrm{DCM}($ Min-EC8) $-\mathrm{DCH}($ Min-EC8) $=\operatorname{Model}(\mathrm{BGL})$

Fig. (7). Mechanical ratio of transverse reinforcement $\omega_{\mathrm{wd}}$ required for $\rho_{\mathrm{t}} \mathrm{m}=0.1$.

$$
\rho_{s} m=A\left(\frac{P}{f_{c}^{\prime} A_{g}}\right)+B
$$

where the coefficients $A$ and $B$ are obtained with a linear regressions from the results of the carried out momentcurvature analyses (Figs. 11 and 12):

$$
\begin{aligned}
& A=\alpha \rho_{t} m+\beta \\
& B=0.0029 \frac{\phi_{u}}{\phi_{y}}-0.0028
\end{aligned}
$$

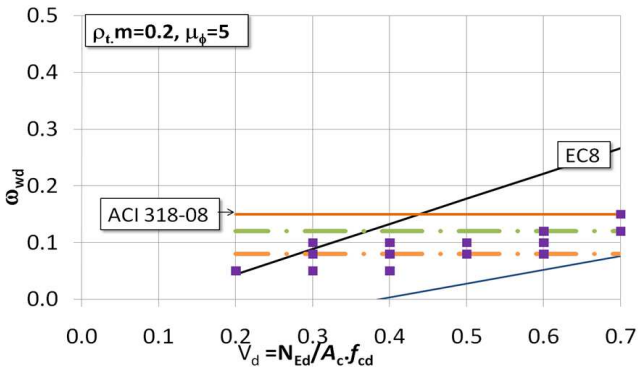

-NZS $3101-$ DCM(Min-EC8) - DCH(Min-EC8) $-\operatorname{Model}($ BGL)

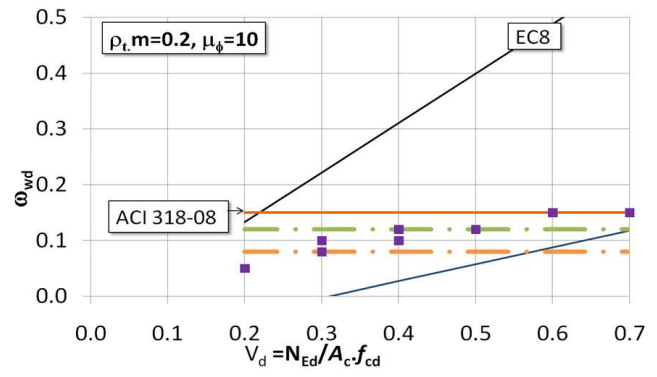

$-\mathrm{NZS} 3101-\mathrm{DCM}(\mathrm{Min}-\mathrm{EC} 8)-\mathrm{DCH}(\mathrm{Min}-\mathrm{EC} 8)=\operatorname{Model}(\mathrm{BGL})$

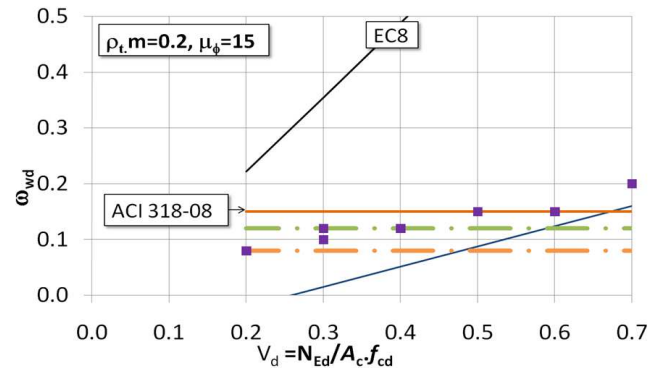

-NZS $3101-\mathrm{DCM}(\mathrm{Min}-\mathrm{EC} 8)-\mathrm{DCH}(\mathrm{Min}-\mathrm{EC} 8)=\operatorname{Model}(\mathrm{BGL})$

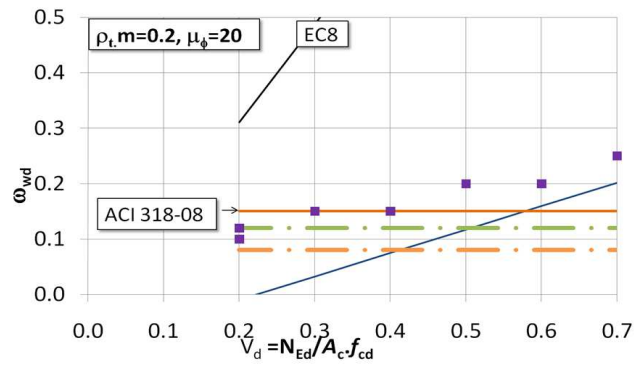

-NZS $3101-\mathrm{DCM}($ Min-EC8) $-\mathrm{DCH}(\mathrm{Min}-\mathrm{EC} 8)=\operatorname{Model}(\mathrm{BGL})$

Fig. (8). Mechanical ratio of transverse reinforcement $\omega_{w d}$ required for $\rho_{\mathrm{t}} \mathrm{m}=0.2$.

$$
\begin{aligned}
& \alpha=-0.0214 \frac{\phi_{u}}{\phi_{y}}-0.2313 \\
& \beta=0.012 \frac{\phi_{u}}{\phi_{y}}+0.1643
\end{aligned}
$$

\subsection{Numerical Analyses on RC Beams Sections}

About 160 monotonic non-linear moment-curvature analyses have been conducted on two different types of RC beam sections: a deep beam and a hidden (concealed) beam. 


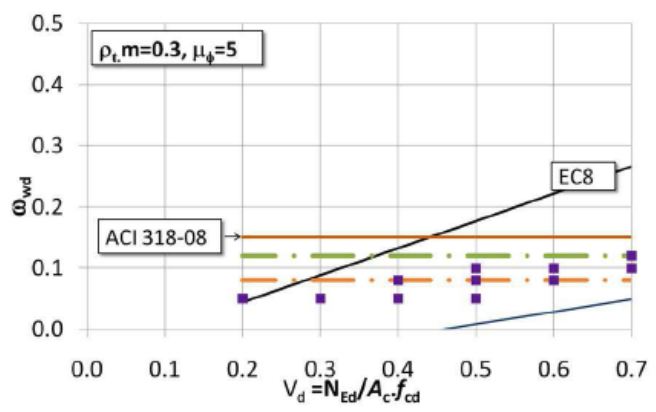

$-\mathrm{NZS} 3101-\mathrm{DCM}($ Min-EC8) $-\mathrm{DCH}($ Min-EC8) $=\operatorname{Model}(\mathrm{BGL})$

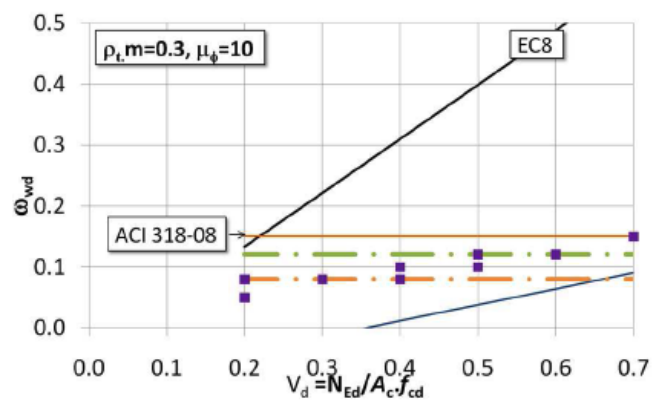

$-\mathrm{NZS} 3101-\mathrm{DCM}(\mathrm{Min}-\mathrm{EC} 8)-\mathrm{DCH}($ Min-EC8) $=\operatorname{Model}(\mathrm{BGL})$

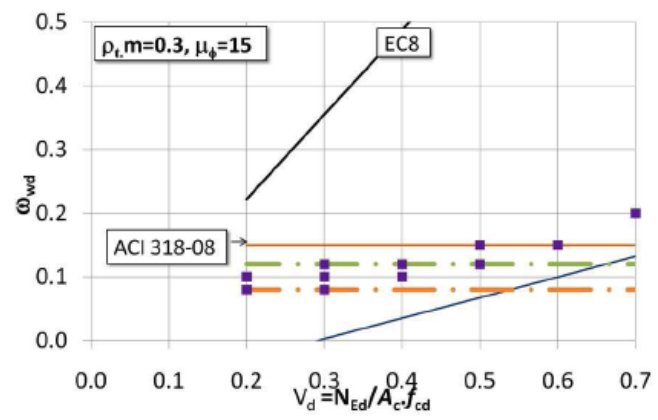

-NZS 3101 -DCM(Min-EC8) - DCH(Min-EC8) $=$ Model(BGL)

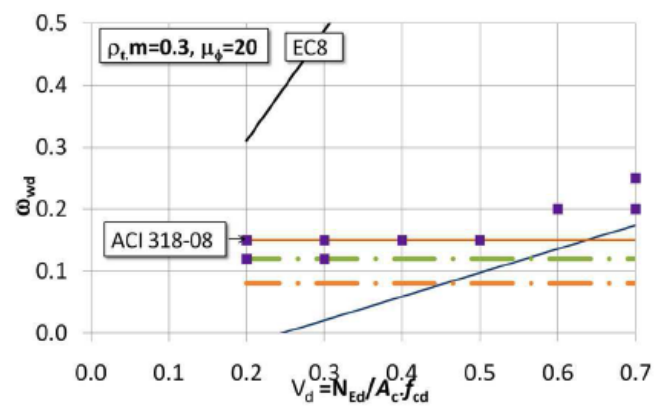

$-\mathrm{NZS} 3101-\mathrm{DCM}(\mathrm{Min}-\mathrm{EC} 8)-\mathrm{DCH}($ Min-EC8) $=\operatorname{Model}(\mathrm{BGL})$

Fig. (9). Mechanical ratio of transverse reinforcement $\omega_{\mathrm{wd}}$ required for $\rho_{\mathrm{t}} \mathrm{m}=0.3$.

Dimensions of the adopted fiber beams sections are reported in Fig. (13). Two different values of the unconfined concrete strength have been considered: $20 \mathrm{MPa}$ and $30 \mathrm{MPa}$. Whereas, the steel strength has been set equal to $450 \mathrm{MPa}$.

Four ratios of longitudinal reinforcement $\rho \% \rho$ have been investigated $(0.25,0.33,0.50$ and 0.67$)$ by considering the following values of the compression reinforcement ratio $\rho$ ': $0.5 \%, 1.0 \%, 1.5 \%$ and $2.0 \%$. For simulating different con-

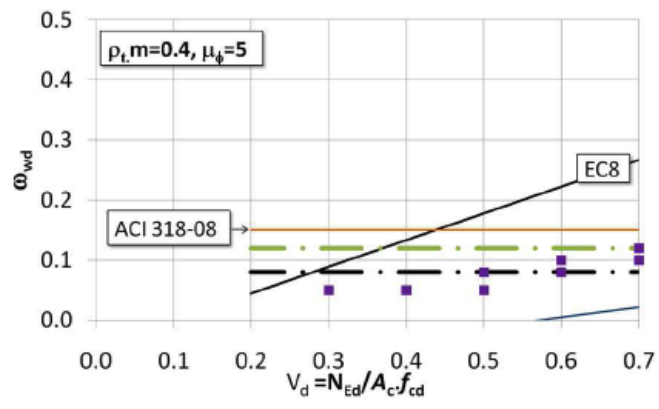

-NZS $3101-\mathrm{DCM}(\mathrm{Min}-\mathrm{EC} 8)-\mathrm{DCH}(\mathrm{Min}-\mathrm{EC} 8)=\operatorname{Model}(\mathrm{BGL})$

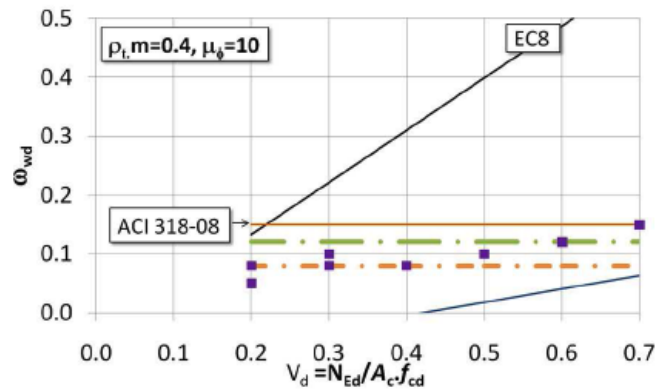

-NZS $3101-$ DCM(Min-EC8) - DCH(Min-EC8) $\mid \operatorname{Model}($ BGL)

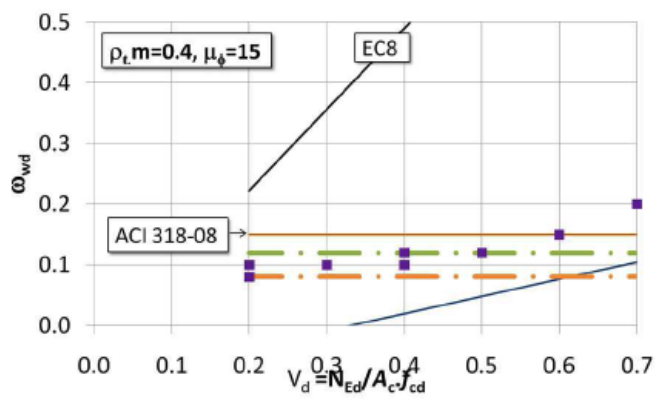

-NZS $3101-$ DCM(Min-EC8) - DCH(Min-EC8) $=$ Model(BGL)

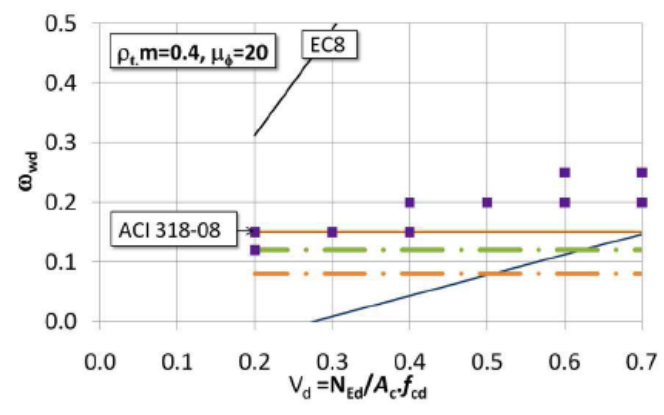

- NZS $3101-$ DCM(Min-EC8) - DCH(Min-EC8) $=\operatorname{Model}($ BGL)

Fig. (10). Mechanical ratio of transverse reinforcement $\omega_{\mathrm{wd}}$ required for $\rho_{\mathrm{t}} \mathrm{m}=0.4$.

finement levels within the section core three hoop spacing have been assigned in the analyses: $25 \mathrm{~mm}, 50 \mathrm{~mm}$ and 200 $\mathrm{mm}$.

In Figs. (14 and 15) the results of the performed analyses are plotted in terms of the evaluated curvature ductility related to the assigned ratio $\rho \% \rho$. In the same figures are reported the curves calculated by the Eq. (16) of the EC8, too. 


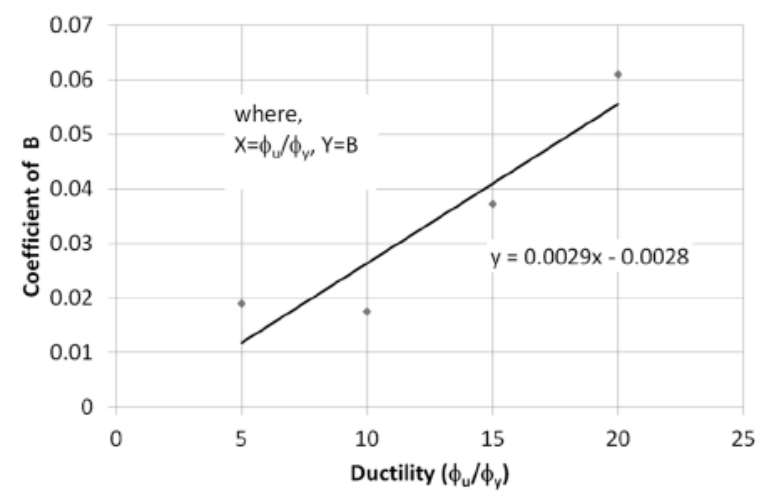

Fig. (11). Determination of the coefficient B.
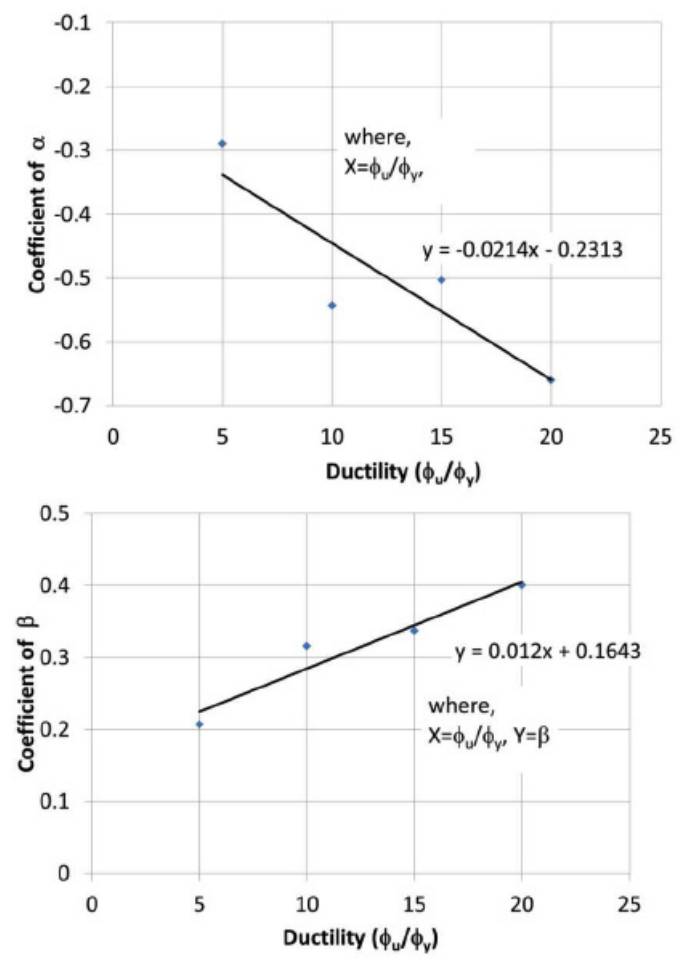

Fig. (12). Determination of the coefficients $\alpha$ and $\beta$.

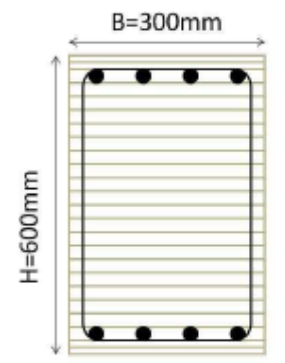

Deep Beam

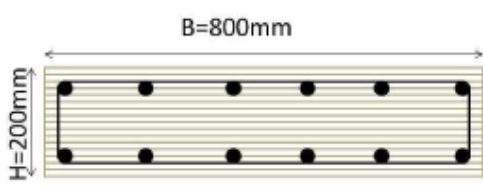

Hidden (Concealed) Beam
Fig. (13). Layout of the considered fiber sections in the analytical investigations of beams.

In the light of the performed comparisons it has been observed that:

- The curvature ductility is influenced by the confinement only if the section is longitudinally over-reinforced (that is the section failure is due to the failure of compressed concrete).

- The curvature ductility for a given ratio $\rho^{\prime} / \rho$ increases as decreases the value of the compression longitudinal ratio $\rho$.

- For a given value of the curvature ductility the EC8 design equation always requires higher values of $\rho^{\prime} / \rho$ than the ones assigned to the sections in the moment-curvature analyses.

- Deep and the concealed beam have both reached the curvature ductility demand required by the studied codes $\left(\mu_{\phi}=10\right.$ and $\mu_{\phi}=16$ in the case of EC 8 and NTC-08 code, and $\mu_{\phi}=16$ and $\mu_{\phi}=20$ in the case of NZS-3101 code).

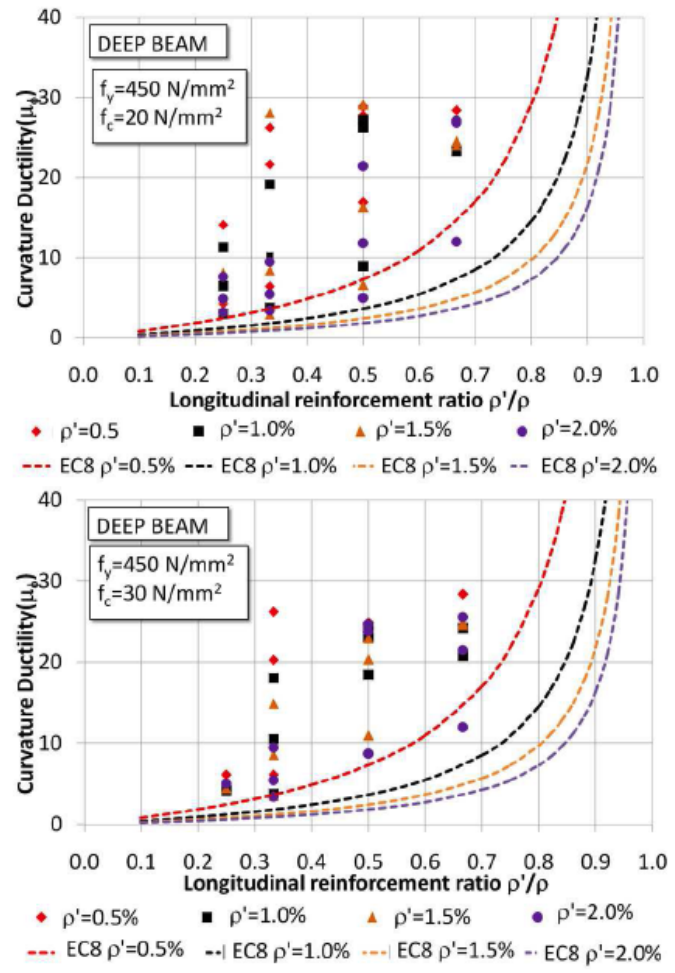

Fig. (14). Curvature ductility obtained for the deep beam analyzed.

\section{CONCLUSION}

In this paper the special provisions has been investigated to be applied to primary elements critical regions of $\mathrm{RC}$ beams and columns in order to ensure the expected curvature ductility. To this scope the design equations of transverse and longitudinal reinforcement amount of four recent seismic codes have been considered and compared among them: the Eurocode 8 (EC8) [1], the Italian Code (NTC-08) [2], the New Zealand Code (NZS-3101) [3] and the American code (ACI-318) [4].

Then monotonic moment-curvature analyses have been conducted on some RC sections of beams and columns detailed with the considered codal detailing rules. The analyses have been carried out in order to evaluate the actual curvature ductility and to compare it with the expected one.

With regard to critical regions of primary seismic columns, the comparisons show that minimum amounts of 
transverse reinforcement indicated by EC 8 and NTC- 08 are not sufficient in many cases in satisfying the curvature ductility demand, even when axial load is moderate.
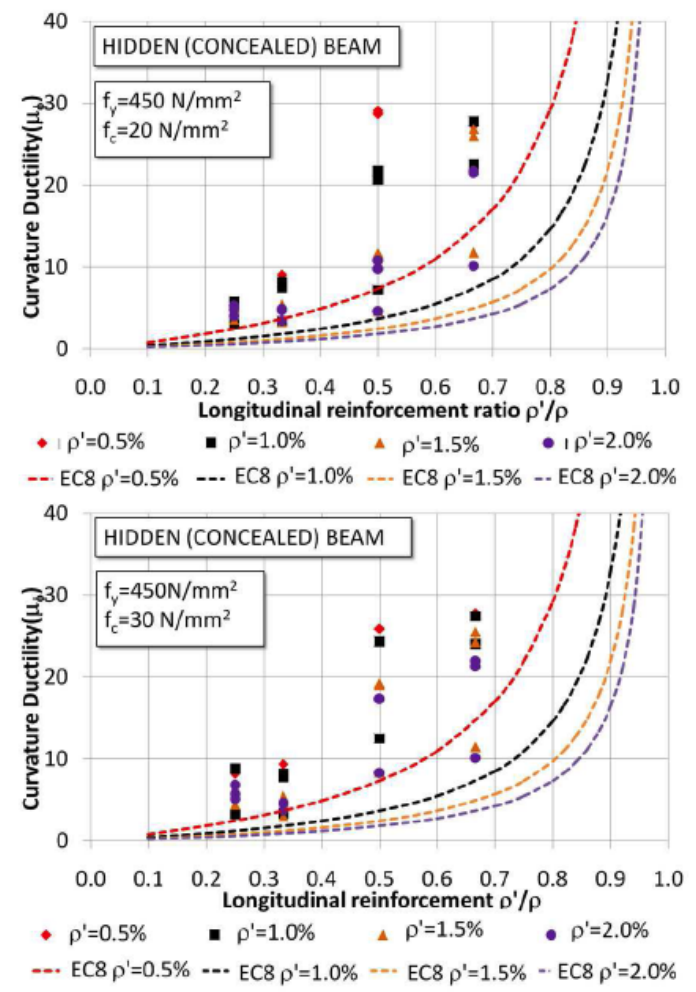

Fig. (15). Curvature ductility obtained for the concealed beam analyzed.

Whereas, the EC8 design equation (Eq. 4) provides significantly higher transverse reinforcement amounts at the base of primary columns than the other codes. Moreover, these amounts are also greater than the assigned ones in the moment-curvature analyses. In many cases when the axial load is high the required EC8 mechanical volumetric ratio of transverse reinforcement is greater than 0.5 (especially in the cases of structures with high ductility class).

As far as longitudinal reinforcement of beams within critical regions is concerned, the design equations of EC8 and NTC-08 provide, for a given value of curvature ductility, a $\rho^{\prime} / \rho$ ratio always greater with respect to the assigned one in the moment-curvature analyses. Moreover, in the analyses carried out both the deep and the concealed beam have reached comparable curvature ductility values. Hence, by referring to the results of this work it is possible to conclude that the beams curvature ductility is independent from the section geometry.

Finally, it has to be remarked that among the considered codes the EC8 has undoubtedly the most conservative approach in designing the reinforcements within critical regions of primary elements.

\section{CONFLICT OF INTEREST}

The authors confirm that this article content has no conflict of interest.

\section{ACKNOWLEDGEMENTS}

Declared none.

\section{REFERENCES}

[1] Eurocode 8. Design of structures for earthquake resistance-Part 1: general rules, seismic actions and rules for buildings, December 2004.

[2] D.M. 14/01/2008. Norme Tecniche per le Costruzioni. S.O. n. 30 of G.U. 04/02/2008 n. 29 (In Italian).

[3] NZS 3101, 2006. Concrete structures standard, part 1- the design of concrete structures and part 2 commentary on the design of concrete structures, Standards Association of New Zealand, Wellington, New Zealand.

[4] ACI 318, 2008. Building code requirements for structural concrete (ACI 318-08) and commentary (ACI 318r-05).

[5] OpenSees, 2009. Open system for earthquake engineering simulation. (http://opensees.berkeley.edu/).

[6] F. Braga, R. Gigliotti, and M. Laterza, "Analytical stress-strain relationship for concrete confined by steel stirrups and/or frp jackets," ASCE Journal Of Structural Engineering, vol. 132, no. 9, pp. 1402-16, 2006.

[7] M. D’Amato, F. Braga, R. Gigliotti, S. Kunnath, and M. Laterza, "A numerical general-purpose confinement model for Non-Linear analysis of R/C Members," Computers and Structures Journal, vol. 102-103, pp. 74-75, 2012.

[8] S. Watson, F.A. Zahn, and R. Park, "Confining reinforcement for concrete columns," ASCE Journal Of Structural Engineering, vol. 120, no. 6, pp. 1798-824, 1994.

[9] S.J. Pantazopoulou, "Detailing for reinforcement stability in R.C. members," ASCE Journal Of Structural Engineering, vol. 124, no. 6, pp. 623-32, 1998.

[10] V. Giamundo, G.P. Lignola, A. Prota, and G. Manfredi, "Effectiveness of FRP wrapping on internal reinforcement buckling for noncircular members," $11^{\text {th }}$ International Symposium on Fiber Reinforced Polymer Reinforcement for Concrete Structures, FRPRCS 2013, Guimaraes, Portugal.

[11] T.C. Rousakis, and A.I. Karabinis, "Adequately FRP confined reinforced concrete columns under axial compressive monotonic or cyclic loading," RILEM Materials and Structures, vol. 45, pp. 957$75,2012$.

[12] F. Braga, R. Gigliotti, M. Laterza, and M. D’Amato. "Progettazione dell'armatura trasversale in funzione della duttilità di curvatura richiesta: prima formulazione di base," Proceeding papers, XIV Convegno ANIDIS, L'ingegneria Sismica In Italia, 18-22 Settembre 2011, Bari (In Italian). 